\title{
La definición del Meridiano Cero en la cartografía histórica
}

Francisco José González González, Real Instituto y Observatorio de la Armada

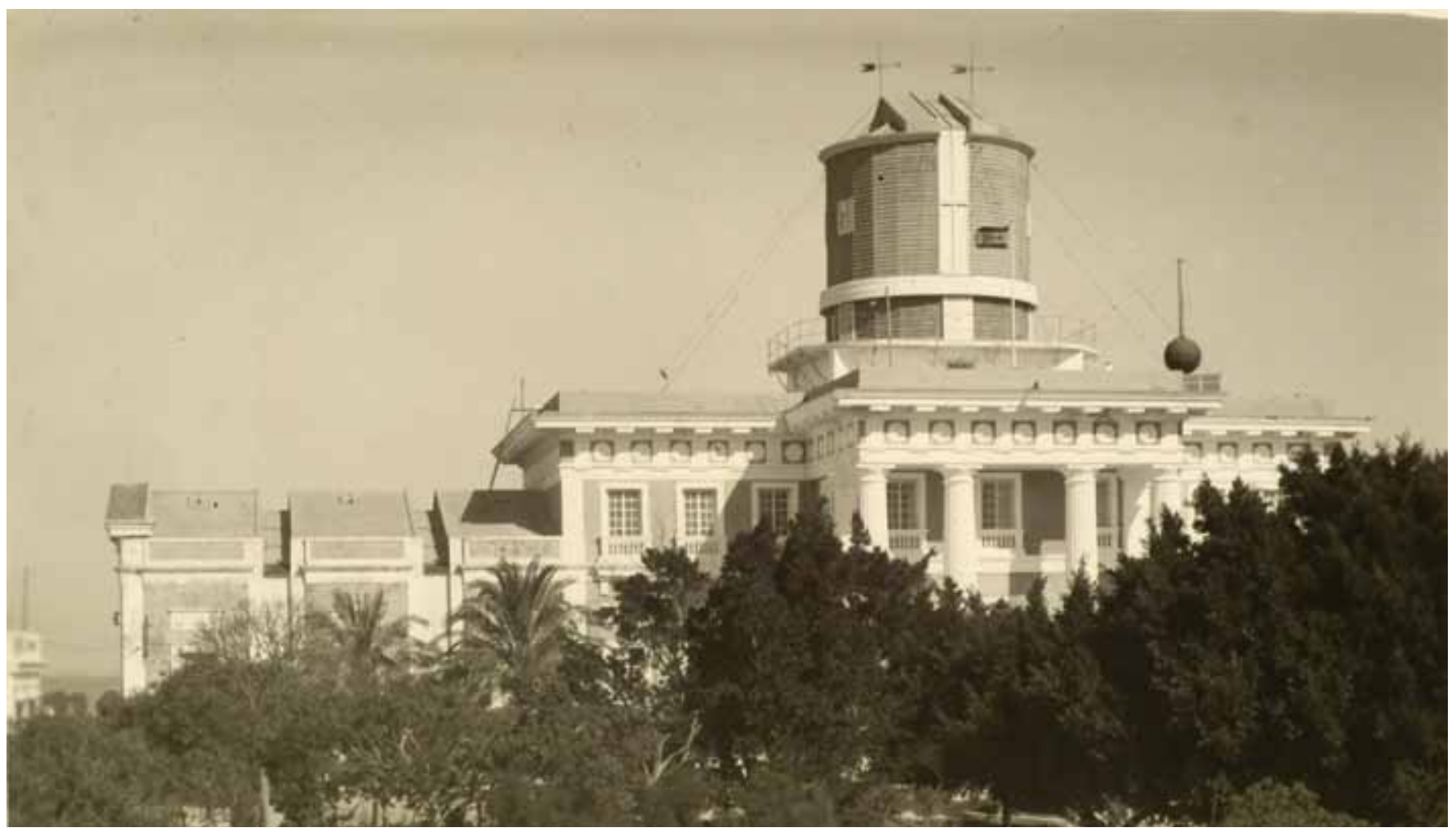

El Observatorio de San Fernando a mediados del siglo XX. Fuente: Archivo Fotográfico del Real Instituto y Observatorio de la Armada

Durante siglos, astrónomos y geógrafos emplearon primeros meridianos diferentes según su época o su país. Ptolomeo utilizó un meridiano situado medio grado al oeste de Canarias. Siglos después, los árabes prefirieron hacer pasar su primer meridiano por el Estrecho de Gibraltar. Durante el siglo XIII, época de Alfonso X el Sabio y de las conocidas Tablas Alfonsinas, el meridiano de origen para astrónomos y navegantes fue el de Toledo. Al inicio de la Edad Moderna, los enfrentamientos entre portugueses y españoles por cuestiones territoriales, derivadas de las grandes navegaciones y descubrimientos de la época, llevaron al establecimiento de la llamada "línea de demarcación", que fue utilizada en la práctica como un verdadero meridiano cero. En el siglo XVI, el célebre geógrafo Mercator introdujo el uso de un nuevo primer meridiano, el de las Azores. Los franceses, un siglo más tarde, comenzaron a elaborar sus cartas náuticas respecto al meridiano que pasa por la parte más occidental de la Isla de El Hierro, un meridiano que, con los cálculos de la época, estaba situado exactamente a 20 grados al oeste del que pasa por el Observatorio de París. De esta forma, sin ser el Meridiano Cero, París $\left(20^{\circ}\right.$ E.) se convertía en el verdadero meridiano de referencia. Mientras tanto, a partir de 1675, los británicos hicieron pasar su primer meridiano por el recién creado Observatorio Real de Greenwich. En la segunda mitad del siglo XVIII, España decidió seguir el ejemplo británico y comenzó a establecer su primer meridiano en Cádiz, donde había sido fundado el Real Observatorio de la Marina en 1753.

Durante el siglo XIX, cada nación continuó utilizando su propio meridiano para cuestiones geográficas y para los mapas terrestres. En lo que se refiere a la navegación no puede decirse que ocurriera lo mismo. El Meridiano de Greenwich fue pronto el más utilizado en las cartas náuticas de todo el mundo, siendo preferido porque a él estaban referidas las efemérides astronómicas publicadas en Gran Bretaña (The Nautical Almanac), que eran usadas en sus cálculos por gran parte de los navegantes de todo el mundo. No obstante, otros países con tradición marítima, como España, Portugal o Francia, continuaron utilizando en su cartografía náutica los meridianos de sus observatorios de referencia. En el caso concreto de España, durante todo el siglo XIX los meridianos de origen usados por los marinos serian el Meridiano de Cádiz y más adelante el de San Fernando, es decir, aquél que pasaba los instrumentos meridianos del Real Observatorio de la Marina. 
En el último tercio del siglo XIX se constata un movimiento científico generalizado favorable a la unificación de signos, lenguajes científicos o medidas (Congresos Meteorológicos, Conferencia Internacional de Pesos y Medidas). Cuando se plantearon las primeras iniciativas para unificar las longitudes terrestres, no existía ninguna razón científica para preferir un meridiano a otro como punto de partida en el cómputo de las longitudes. No obstante, la decisión sobre este asunto se vio retrasada por factores nacionalistas basados en el presunto prestigio que pudiese reportar a una nación el hecho de que en ella se determinase el Meridiano Cero.

Asi estaban las cosas cuando, en octubre de 1883, se celebró la Conferencia Geodésica Internacional de Roma, a la que acudieron, entre otros, los directores de los principales observatorios y los delegados de todos los Estados miembros de la Asociación. Los temas tratados en la conferencia fueron la posibilidad de unificar el cómputo de las longitudes, mediante la adopción de un primer meridiano único, y la creación de una hora universal, necesaria especialmente para todo lo relacionado con las comunicaciones internacionales.

Las propuestas acordadas por los participantes en la reunión de Roma encontraron un ambiente favorable en los ámbitos científicos y políticos. Sólo un año después, en 1884, el Gobierno de los Estados Unidos de América convocaria la Conferencia Internacional de Washington para la adopción de un Primer Meridiano Universal y de una Hora Cosmopolita. En Washington se acordó proponer a los gobiernos representados en el Congreso la adopción del Meridiano de Greenwich como Meridiano Magistral de Longitudes, a partir del cual la longitud se contaría en dos direcciones de $0^{\circ}$ a $180^{\circ}$ [la longitud este positiva (+) y la oeste negativa (-)]. Estas decisiones afectarian directamente al cómputo de la hora, pues también se acordó que el Día Universal debía empezar para todo el mundo a partir de la media noche-media del Primer Meridiano, dividiéndose su duración en 24 horas que darian lugar al sistema de los husos horarios.

No obstante, las resoluciones aprobadas en Washington no tuvieron la rápida aplicación que sus partidarios hubieran deseado. Las reticencias de algunos importantes paises a aceptar el Meridiano de Greenwich como el primero, especialmente las de Francia, las dificultades técnicas derivadas de la necesaria reforma de las efemérides y la existencia de cartas náuticas y mapas referidos a otros meridianos fueron retrasando año tras año la adopción de un sistema con el que, sin embargo, todos parecian estar de acuerdo.

Diez años más tarde, España, al igual que otros paises europeos, aún no se había decidido a llevar a cabo unas reformas cuyos representantes habian aceptado en la Conferencia de Washington. Tampoco se había adoptado en nuestro país el sistema de los husos horarios según el cual España quedaba incluida, para el cómputo de las horas locales, en la llamada Hora del Oeste de Europa (Hora de Greenwich). En los últimos años del siglo pasado todavía era considerada en España la hora oficial como aquella correspondiente al meridiano de cada localidad, es decir, no habia una hora oficial común para todo el territorio nacional que pudiese ser utilizada como hora local españo-

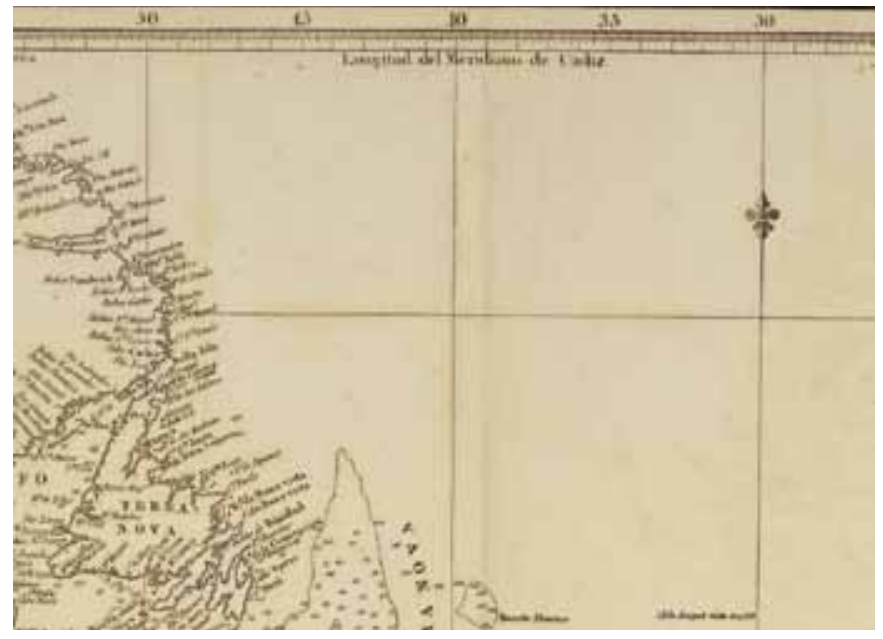

Detalle de una carta náutica referida al Meridiano de Cádiz. Fuente: Colección de Cartografía del ROA. N. . INV. ROA 0001-M

\section{El meridiano de Hierro y meridiano}

del Pico Teide: en el congreso de matemáticos y astrónomos, celebrado en París en 1634 y presidido por el rey de Francia Luis XIII, se fijó como meridiano de referencia el que pasa por el extremo más occidental de la isla de Hierro (cabo de Orchilla), que fue aceptado por toda la cristiandad, excepto por los holandeses, que lo fijaron en el Teide

la. Únicamente los ferrocarriles tenían unificados sus horarios según la hora del Meridiano de Madrid.

No sería hasta 1901 cuando se decidiese definitivamente el establecimiento de la hora oficial española de acuerdo con la del Meridiano de Greenwich. Unos años más tarde, en abril de 1907, se adoptó el Meridiano de Greenwich como primer meridiano para usos navales. Poco después, el Ministro de Marina ordenó a la Dirección de Hidrografia que todas las cartas náuticas grabadas a partir de entonces utilizasen el Meridiano de Greenwich como origen de longitudes. Esta misma disposición oficial ordenó que el Almanaque Náutico para 1910 fuese calculado utilizando Greenwich, y no San Fernando, como meridiano de referencia, y que los cronómetros de la Armada fueran arreglados a la hora del Meridiano de Greenwich.

\section{Bibliografía}

GONZÁLEZ GONZÁLEZ, F. J. (1992) El Observatorio de San Fernando (18311924). Madrid: Ministerio de Defensa, 1992

HOWSE, D. (1985) 1884 and Longitude Zero. Vistas in astronomy, 28, 1985, pp. 12-19

MARTÍN-MERÁS, L. (coord.) (2003) La Dirección de Trabajos Hidrográficos (17971908). Madrid: Ministerio de Defensa, Secretaria General Técnica, 2003, 2 v. PASTORÍN Y VACHER, J. (1885) Memoria sobre el Congreso Internacional de Washington. Revista General de Marina, XVI (1885), pp. 623-685, 835-866 y 979-1079 